\title{
Life prediction of Ni-base superalloy
}

\author{
M AGHAIE-KHAFRI* and M NOORI \\ Faculty of Mechanical Engineering, K.N. Toosi University of Technology, Tehran, Iran
}

MS received 11 January 2011; revised 4 February 2011

\begin{abstract}
Rene 80 samples were creep-rupture tested in air between 1144 and $1255 \mathrm{~K}$ at various stress levels. The mean stress exponent, $n$, and the mean activation energy for creep were calculated from the experimental results. The accelerated creep life of the alloy was evaluated by using iso-stress parametric equations and Monkman-Grant method.
\end{abstract}

Keywords. Rene 80; creep rupture; life prediction.

\section{Introduction}

Superalloys have found widespread engineering applications mainly due to a high degree of strength and creep properties coupled with oxidation and corrosion resistance at elevated temperatures. Hot sections of gas turbines are exposed to high temperatures and stresses during service and, for this reason, are usually made from heat-resistant investment cast Ni-base superalloys (Maccagno et al 1990). These components are expensive and there is considerable incentive to assess their service lives (Kim et al 2008). High temperature components can be life-limited by creep damage under thermomechanical loading. Therefore, the correlation between rupture life and creep characteristics was the subject of the various studies which suggested some accurate methods for predicting creep life during long time, high temperature service (Larson and Miller 1952; Orr et al 1954). The iso-stress extrapolation methods are based on the iso-stress lines in a graph with coordinates log (rupture time) versus $1 / T$ or $T$. Moreover, many equations relating the secondary or steady state creep rate to rupture life have been proposed to analyse data from constant load accelerated uniaxial creep tests (Monkman and Grant 1956). Consequently, if for a given material the constants related to each equation are determined, thereby the rupture time can be predicted just by measuring the steady state-creep rate. Other methodologies exhibiting more flexibility to parametric analysis of creep data have also been proposed (Viswanathan 1989).

Rene 80 is an investment casting superalloy which is widely used in applications requiring strength at high temperature, especially for blades and vanes in gas turbines. This alloy is age-hardenable by a fine dispersion of $\gamma^{\prime}$ particles, which have an ordered face-centred cubic structure. The mechanical properties of the alloy are strongly dependent upon the size and distribution of the $\gamma^{\prime}$ precipitates. The

*Author for correspondence (maghaei@kntu.ac.ir) objective of this study is to investigate the accelerated creep behaviour of Rene 80 superalloy between 1144 and $1255 \mathrm{~K}$ at various stress levels.

\section{Experimental}

The material used in this investigation was the cast Ni-base polycrystalline superalloy Rene 80, supplied by Ross and Catheral Co., UK. The chemical composition of the alloy is given in table 1.

The master alloy $(5 \mathrm{~kg})$ was melted by vacuum induction and poured into the ceramic cluster moulds in a $25 \mathrm{~kg}$ Leybold Heraeus two-chamber vacuum-induction furnace. Vacuum during melting and casting was $1.3 \times 10^{-3}$ and $1.2 \times 10^{-2} \mathrm{~Pa}$, respectively. The cluster mould arrangement was six cylindrical castings, $18 \mathrm{~mm}$ in diameter and $100 \mathrm{~mm}$ in length around the central sprue. Cylindrical bars, $7 \mathrm{~mm}$ in diameter and $70 \mathrm{~mm}$ long were machined out of the cast material and then the M6 creep test specimens were prepared from the bars according to the ASTM-E8. All the test specimens were made from the same melt and subjected to the standard heat treatment (SHT).

The SHT for Rene 80 included the following steps. Step 1: $1477 \mathrm{~K}, 2 \mathrm{~h}$, then furnace cooled to $1366 \mathrm{~K}$ within $10 \mathrm{~min}$. Step 2: held at $1366 \mathrm{~K}, 4 \mathrm{~h}$, furnace cooled to $922 \mathrm{~K}$ within $60 \mathrm{~min}$, held at $922 \mathrm{~K}$ for $10 \mathrm{~min}$. Step 3: raised temperature to $1327 \mathrm{~K}$ and held for $4 \mathrm{~h}$, then cooled to $922 \mathrm{~K}$ within the range of $15-60 \mathrm{~min}$ and held for $10 \mathrm{~min}$. Step 4: raised temperature to $1116 \mathrm{~K}$ and held for $16 \mathrm{~h}$, then air cooled to room temperature.

The creep tests were carried out in air at a temperature range of 1144-1255 K and a stress range of 191-446 MPa. The creep strains in the gauge section were measured by a linear variable differential transformer attached to an extensometer frame which was also attached to the creep specimen. The creep tests were performed until the rupture of the 
Table 1. Chemical composition of Rene 80 in wt.\%.

\begin{tabular}{ccccccccccccc}
\hline & $\mathrm{Cr}$ & $\mathrm{C}$ & $\mathrm{Mo}$ & $\mathrm{W}$ & $\mathrm{Ti}$ & $\mathrm{Nb}$ & $\mathrm{Co}$ & $\mathrm{Al}$ & $\mathrm{B}$ & $\mathrm{Fe}$ & $\mathrm{Zr}$ & $\mathrm{Ni}$ \\
\hline Rene 80 & 13.4 & 0.16 & 4.11 & 3.92 & 4.77 & 0.03 & 9.45 & 2.12 & 0.02 & 0.10 & 0.04 & Balance \\
\hline
\end{tabular}

specimens. The temperature was monitored by three type $\mathrm{K}$ thermocouples and maintained within about $\pm 2 \mathrm{~K}$.

For scanning electron microscopy examination, Rene 80 samples were electro-polished with a solution of $10 \% \mathrm{HCl}+$ methanol at $20 \mathrm{~V}$ for $20 \mathrm{~s}$ and electro-etched with $170 \mathrm{ml}$ phosphoric acid $+10 \mathrm{ml}$ sulfuric acid and $16 \mathrm{~g}$ chromium trioxide at room temperature and $5 \mathrm{~V}$ for 3-5 s.

\section{Results and discussion}

The multi-phase microstructures of the heat-treated Rene 80 samples mainly consist of $f c c \gamma$ Ni-base matrix, carbides and dispersion of the intermetallic $\gamma^{\prime}$ precipitate phase, which is shown in figure 1. Solid solution strengthening of the $f c c$ $\gamma$ Ni-base matrix and high volume fraction (45-50\%) of $\gamma^{\prime}$ precipitate having the ordered structure of the $\mathrm{Cu}_{3} \mathrm{Au}$-type, result in the extraordinary high temperature properties of the alloy (Safary and Nategh 2006).

\subsection{Creep curves}

Typical creep curves for Rene 80 at different test conditions are shown in figure 2. The creep curves like most Ni-base superalloys show three distinct regions. After the instantaneous strain, $\varepsilon_{0}$, a decelerating strain rate stage (primary creep) leads to a steady minimum creep rate, $\dot{\varepsilon}_{\mathrm{S}}$ (secondary creep), which is finally followed by an accelerating stage (tertiary creep) that ends in fracture at a rupture time, $t_{\mathrm{r}}$ (Viswanathan 1989). It is worth noting that the minimum creep rate increases with increasing temperature or stress, causing accelerated rupture at higher temperature or stress.

The creep behaviour is a function of temperature, stress, structural factor and chemical compositions, and the like (Swindemana and Swindeman 2008). It can be expressed using the following empirical equation (Ray et al 2007):

$$
\dot{\varepsilon}=A \sigma^{n} \exp \left(-\frac{Q}{R T}\right),
$$

where $\dot{\varepsilon}$ is strain rate, $A$ a constant, $\sigma$ the engineering stress, $n$ the stress exponents for creep, $R$ the universal gas constant, $T$ the absolute temperature and $Q$ the activation energy for creep. Using a regression program, the mean activation energy and the mean stress exponent were calculated as $210 \pm 14 \mathrm{Kcal} / \mathrm{molK}$ and $9 \cdot 4 \pm 3 \cdot 2$, respectively.

\subsection{Iso-stress methods}

The methods of Orr-Sherby-Dorn, Larson-Miller and Manson-Succop are based on the iso-stress lines in a graph with coordinates $\log (\operatorname{tr})$ versus $1 / T$ or $T$ (tr, rupture time, $T$,

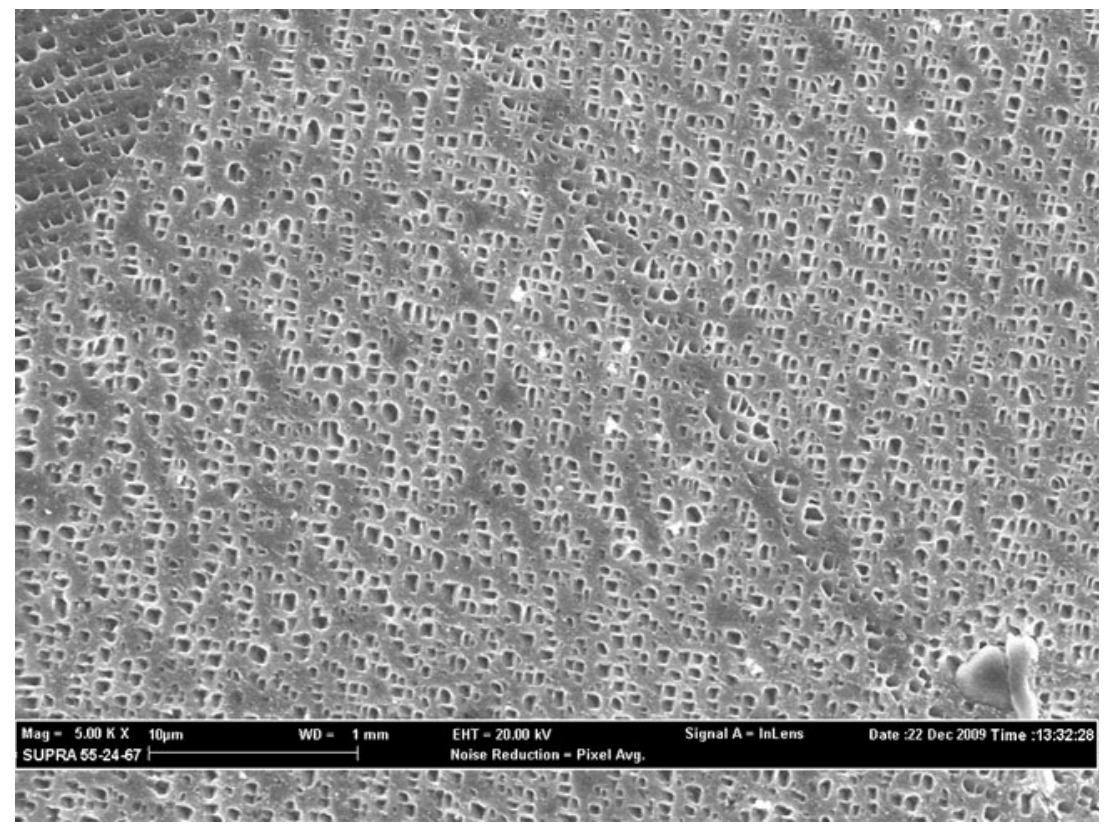

Figure 1. SEM (back scatter) microstructure of the Rene 80 sample after SHT. 

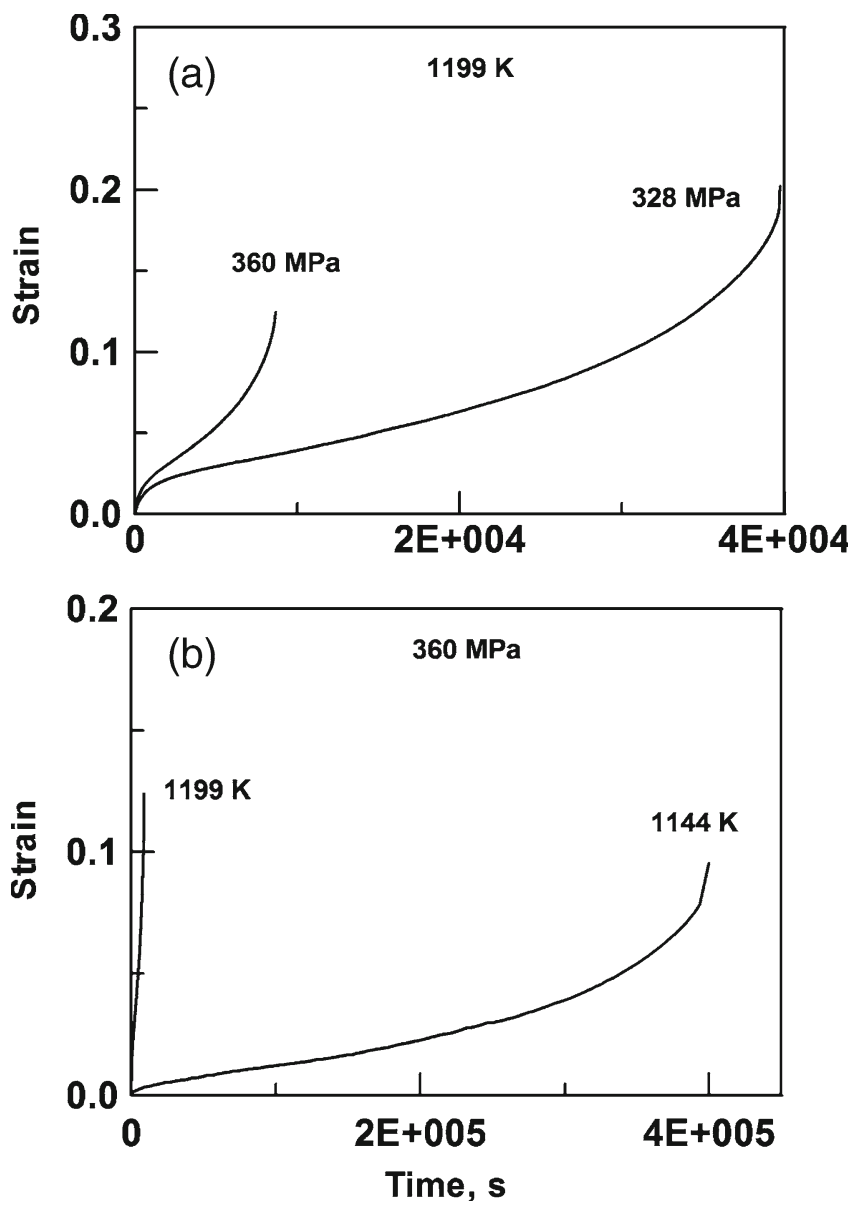

Figure 2. Typical creep curves of Rene 80 samples at different test conditions.

test temperature) (Bueno and Sordi 2008). The Orr-SherbyDorn life prediction method is on the basis of a parameter that is derived by considering the expression for the secondary creep strain rate at constant stress (Orr et al 1954):

$$
P_{\mathrm{OSD}}=\log t_{\mathrm{r}}-\frac{Q}{R T}
$$

where $t_{\mathrm{r}}$ is the time to rupture at temperature $T, Q$ a characteristic activation energy for the process and $R$ the universal gas constant. The Larson-Miller parameter is similar to the Sherby-Dorn parameter but different assumptions were made in its derivation (Larson and Miller 1952):

$$
P_{\mathrm{LM}}=T\left(\log t_{\mathrm{r}}+C\right),
$$

where $C=\mathrm{L}-\mathrm{M}$ constant $=20$ for many materials, $T=$ test temperature in $K$ and $t_{\mathrm{r}}=$ time to rupture in hours. Figure 3 shows the Sherby-Dorn and Larson-Miller parameter diagrams for Rene 80 superalloy. It is worth noting that the Larson-Miller method is a reliable technique for life prediction as long as the alloy microstructure is stable during prolonged exposure at high temperature (Koul and Castilo 1988; Marahleh et al 2006).
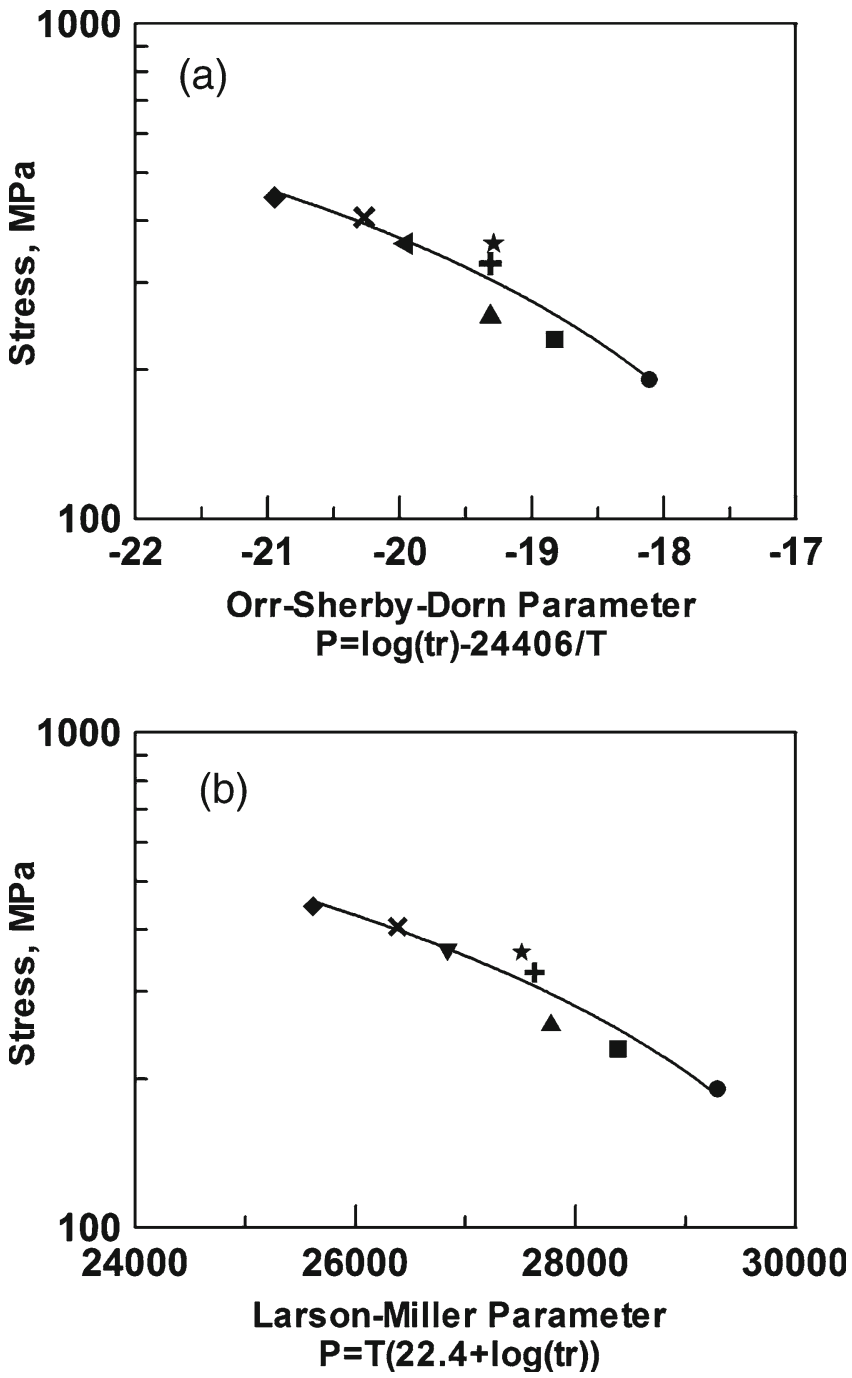

Figure 3. The Orr-Sherby-Dorn (a) and Larson-Miller (b) parameter diagrams; - $191 \mathrm{MPa} / 1255 \mathrm{~K}$, $230 \mathrm{MPa} / 1255 \mathrm{~K}$, \ $260 \mathrm{MPa} / 1255 \mathrm{~K}, 328 \mathrm{MPa} / 1199 \mathrm{~K}$, $360 \mathrm{MPa} / 1199 \mathrm{~K}$, $\star 360 \mathrm{MPa} / 1144 \mathrm{~K}$, x $406 \mathrm{MPa} / 199 \mathrm{~K}, 446 \mathrm{MPa} / 144 \mathrm{~K}$.

The method of Manson-Succop is based on the parallelism of the iso-stress lines, with same slope $B$, in a graph $\log (\operatorname{tr})$ versus $T$, in the following way (Bueno and Sordi 2008):

$$
P_{\mathrm{MS}}=\log \left(t_{\mathrm{r}}\right)-B T,
$$

where $t_{\mathrm{r}}$ is rupture time, $T$ the temperature, and $B$ is a constant. Figure 4 shows the Manson-Succop parametric curve, which offered the highest degree of fit among the iso-stress methods employed in this study.

\subsection{Monkman-Grant method}

Monkman and Grant (1956) found that, for many alloy systems, the relation between the minimum creep rate $\left(\dot{\varepsilon}_{\mathrm{s}}\right)$ and time to rupture $\left(t_{\mathrm{r}}\right)$ can be expressed as follows:

$$
\left(\dot{\varepsilon}_{\mathrm{s}}\right)^{m} \cdot t_{\mathrm{r}}=C
$$




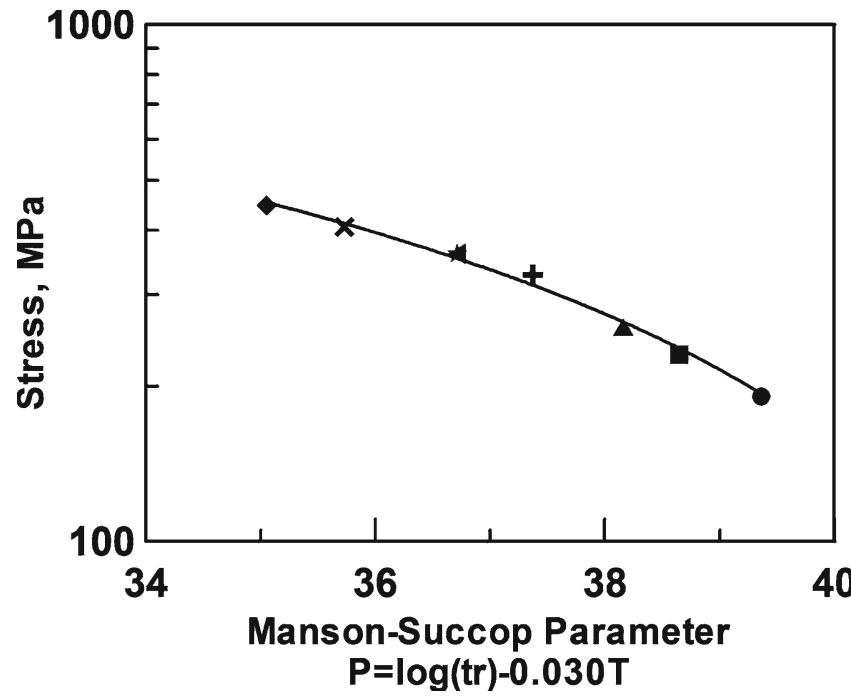

Figure 4. Manson-Succop parametric curve, where the description of symbols is the same as in figure 3 .

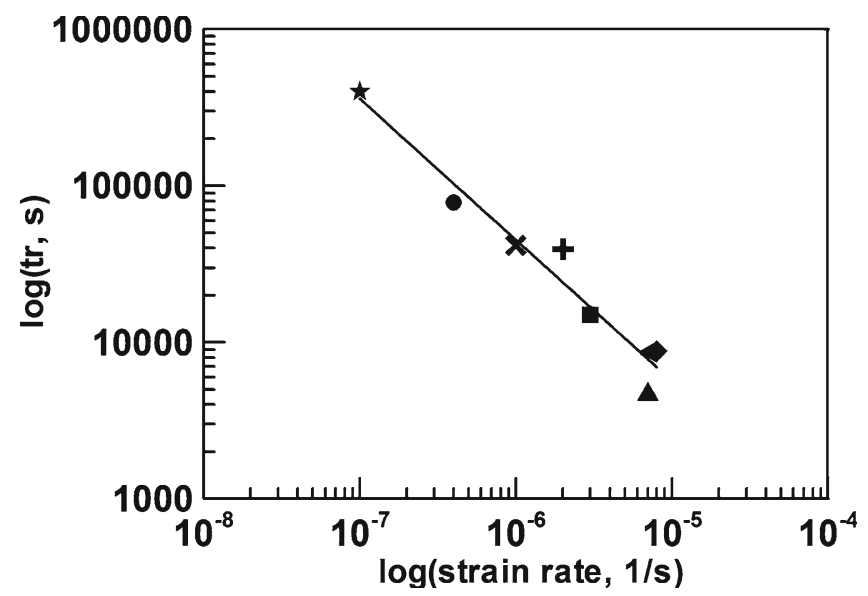

Figure 5. Graphical representation of Monkman-Grant equation for Rene 80, where the description of symbols is the same as in figure 3 .

where $m$ and $C$ are material constants. The logarithmic form of (5) is graphically represented in figure 5. The experimental data have a reasonable agreement in the case of Rene 80.

During an investigation on the creep life predictions, Koul et al (1984) and Castilo et al (1987) claimed that in the case of complex alloys, stress-rupture data exhibits high scatter, and that the Monkman-Grant relationship is unable to distinguish degenerative effects caused during service. They proposed a modified equation which isolates the tertiary stage of creep life and creep strain from creep data. The modified Monkman-Grant equation is written as

$$
t_{\mathrm{t}}=K \dot{\varepsilon}_{\mathrm{s}}^{n}
$$

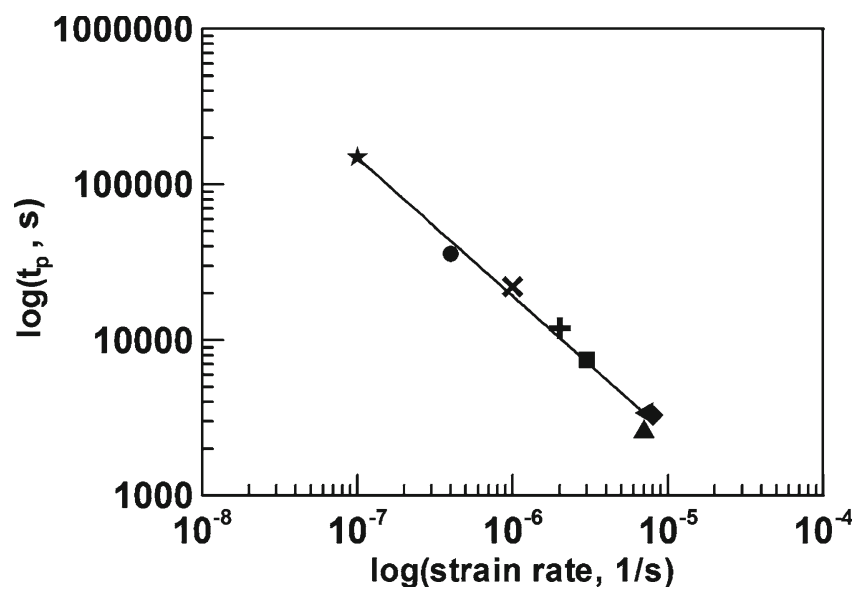

Figure 6. Time-to-tertiary creep versus minimum creep rate in Rene 80 , where the description of symbols is the same as in figure 3.

where $t_{\mathrm{t}}$ the time-to-tertiary creep, is the sum of the primary and secondary creep lives $\left(t_{\mathrm{p}}+t_{\mathrm{s}}\right) ; n$ and $K$ are material constants. Time-to-tertiary creep versus minimum creep rate for Rene 80 samples are shown in figure 6. It is clear that modified Monkman-Grant equation is in fair agreement with experimental data.

\section{Conclusions}

Based on the present study on the accelerated creep rupture behaviour of Rene 80 superalloy, the following conclusions can be made:

- The minimum creep rate increases with increasing temperature or stress, causing accelerated rupture at higher temperature or stress.

- Iso-stress life prediction methods can be used to extrapolate the results obtained from accelerated creep rupture test. The Manson-Succop method offered the highest degree of fit.

- Both the Monkman-Grant equation and its modified version were found suitable for life assessment of Rene 80 superalloy.

- The mean activation energy for creep was calculated as $210 \pm 14 \mathrm{Kcal} / \mathrm{molK}$.

\section{References}

Bueno L O and Sordi V L 2008 Mater. Sci. Eng. A483-484 560 Castilo R, Koul A K and Toscano E H 1987 ASME J. Eng. Gas Turb. Power 10999

Kim D H, Kim J H, Sa J W, Lee Y S, Park C K and Moon S 2008 Mater. Sci. Eng. A483-484 262

Koul A K and Castilo R 1988 Metall. Trans. A19 2049

Koul A K, Castillo R and Willett K 1984 Mater. Sci. Eng. 66213 
Larson F R and Miller J 1952 Trans. ASME 756

Maccagno T M, Koul A K, Immarigeon J P, Cutler L, Allem R and Lesperance G 1990 Metall. Trans. A21 3115

Marahleh G, Kheder A R I and Hamad H F 2006 Mater. Sci. Eng. A433 305

Monkman F C and Grant N J 1956 Proc. ASTM 56593

Orr R, Sherby O D and Dorn J E 1954 Trans. ASME 46113
Ray A K, Diwakar K, Prasad B N, Tiwari Y N, Ghosh R N and Hittenberger J D 2007 Mater. Sci. Eng. A454-455 124

Safary J and Nategh S 2006 J. Mater. Proc. Tech. 176240

Swindemana R W and Swindeman M J 2008 Int. J. Press. Vess. Piping $\mathbf{8 5} 72$

Viswanathan R 1989 Damage mechanisms and life assessment of high-temperature components (Ohio: ASM International) p 59 